\title{
Computer Simulation to Manage Lean Manufacturing Systems
}

\author{
Ahmed Deif \\ Department of Industrial Systems Engineering, University of Regina \\ Regina, SK, Canada \\ ahmed.deif@uregina.ca
}

\begin{abstract}
There is a difference between a lean manufacturing system and a manufacturing system that just applies lean techniques. This paper addresses the previous statement through using computer simulation to explore the impact of applying just in time lean policy on a traditional inventory based production system. A system dynamics model is introduced to capture the different components of the production system. The inventory dynamics of the modeled system is examined against different production scenarios under stochastic demand. Results showed that in systems that are not fully transferred to lean, adopting lean principles are not always beneficial. The paper suggests some specific management policies for successful lean application within the scope of the modeled manufacturing system
\end{abstract}

Keywords-simulation, lean manufacturing, management

\section{INTRODUCTION}

Lean manufacturing provides a way to do more and more with less and less. Lean manufacturing achieves the previous objective through a group of methods and tools that eliminate wastes in the manufacturing system and focus on the value added activities. In lean manufacturing, value can only be defined by the ultimate customer [1]. Sanchez and Nagi [2] simply define lean as a collection of operational techniques focused on productive use of resources Another definition that highlights the human and the variability aspects is proposed in [3] where they define lean manufacturing as an integrated socio-technical system whose main objective is to eliminate waste by concurrently reducing supplier, customer, and internal variability

With the previous advantages stated and with statements like "lean manufacturing is the dominant force changing the face of manufacturing as we know it" [4]; one can expect a strong transformation wave toward this manufacturing paradigm. However, there is a difference between a lean manufacturing system and a manufacturing system that just applies lean techniques. Usually practitioners expect many of the lean fruits through employing as much lean tools as possible while the reality is different. To have full benefit of lean manufacturing paradigm, systems should undergo substantial change in terms of both culture and infrastructure. By culture, we mean the organizational management and employers' engagement to lean principles and by infrastructure we refer to the technical and layout modification required by lean design. This paper highlights one aspect of the previous challenge where the inventory dynamics of a traditional production system is investigated upon the employment of just in time JIT lean policy.
The details and description of the classical lean manufacturing system's philosophies and tools are well documented by some of the early researchers of the lean system (examples include: [5] and [6]). A recent review on lean manufacturing can be found in [3]. There are many attempts in the literature to describe how to implement lean manufacturing (examples include: [7] and [8]) or how lean manufacturing will improve the manufacturing systems performance (examples include: [9], [10] and [11]).

On the other hand, the literature has much fewer attempts to explore the lean manufacturing dynamics. Most of the work includes simulation studies that were also conducted to investigate the impact of just in time (JIT) and pull lean principles on improving manufacturing system performance [12], [13], [14] and [15]. This paper adds to the few existing approaches through exploring how lean principle application can impact the dynamics of traditional production systems

\section{COMPUTER SIMULATION MODEL FOR PRODUCTION}

Figure 1 shows the system dynamic model for a traditional production system. The model aggregates the production details in order to capture various component of the system. The presented model is typical traditional production system which where the production is decided based on demand as well as desired work in progress (WIP) and inventory levels. In this paper, a continuous-time model is used because it provides an acceptable approximation of the production dynamics at that level of abstraction and aggregation [16].

\section{A. Model Nomenclature}

Let $B(t)=$ the backlog level at time $t$.

$I(t)=$ the inventory level at time $t$.

$W I P(t)=$ the WIP level at time $t$.

$D W I P(t)=$ the desired WIP level at time $t$.

$A W I P=$ the WIP adjustment.

$W A T=$ the WIP adjustment time

$P R(t)=$ the production rate at time $t$.

$\operatorname{PSR}(t)=$ the production start rate at time $t$.

$\operatorname{DPSR}(t)=$ the desired production start rate at time $t$.

$D P(t)=$ the desired production rate at time $t$.

$C O(t)=$ the customer order rate at time $t$.

$O R(t)=$ the order rate at time $t$. .

$O F R(t)=$ the order fulfillment rate at time $t$.

$S T=$ the shipment time. 


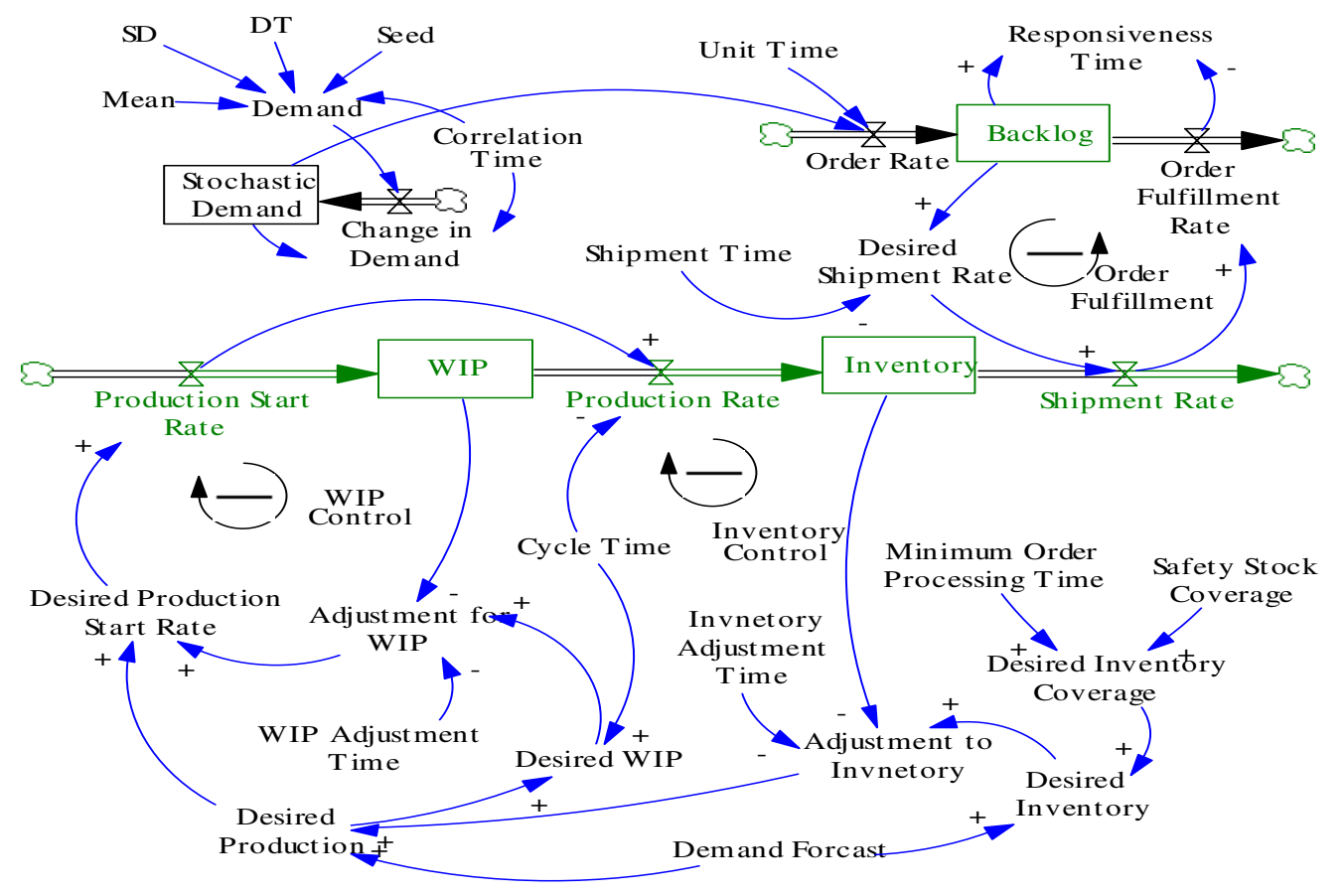

Figure 1. Model structure for traditional production system

$\operatorname{DSR}(t)=$ the desired shipment rate at time $t$.

$\operatorname{ShR}(t)=$ the shipment rate at time $t$.

$\operatorname{MSR}(t)=$ the maximum shipment rate at time $t$.

$M O P T=$ the minimum order processing time.

$S S C=$ the safety stock coverage time.

$D I C=$ the desired inventory coverage time.

$I A T=$ the inventory adjustment time.

$D I(t)=$ the desired inventory level at time $t$. .

$A I(t)=$ the adjustment for inventory rate at time $t$.

$C T=$ the cycle time.

\section{B. Model Logic}

Stochastic Market Demand:

The market demand is modeled as a stochastic demand parameter with dependent distribution. The demand is assumed to have a continuous cumulative normal distribution function. Equation 1 formulates the demand as white noise with a normal distribution.

$$
\operatorname{Demand}(\mathrm{t})=\mathrm{AD}(\mathrm{t})+\left[S D^{2} * \frac{(2-(D T / \operatorname{Cor} T))}{(D T / \operatorname{Cor} T)}\right]^{0.5} * \operatorname{Normal}(0,1, \text { Seed })
$$

Equations 2 and 3 display the values for the stochastic demand and the change in demand.

StochasticDemand $(\mathrm{t})=$ Changein $\operatorname{Demand}(\mathrm{t})$ - Demand $(\mathrm{t})$

Change in Demand $(\mathrm{t})=\frac{\text { Stochastic Demand }(\mathrm{t})-\operatorname{Demand}(\mathrm{t})}{\text { CorT }}$

Inventory Control:

The inventory control mechanism in the developed model follows the same one introduced in [17]. The inventory adjustment is controlled by the inventory gap between desired and current inventory levels (equation 4).

$$
A I(t)=\frac{D I(t)-I(t)}{I A T}
$$

The desired inventory level is calculated using equations (5 and 6) to ensure enough coverage of products for the forecasted demand.

$$
\begin{aligned}
& D I(t)=\text { DemandForcast } * \text { DIC } \\
& D I C=M O P T+S S C
\end{aligned}
$$

The desired inventory coverage includes two components: First, the manufacturer should maintain enough coverage to ship at expected rate requiring a base coverage level equal to MOPT. Second, adding safety stock coverage (SSC) to ensure a good level of service.

The current inventory level is controlled by equation (7).

$$
I(t)=P R(t)-\operatorname{Sh} R(t)
$$

Production Control:

The WIP level is determined by the difference between the production start rate and the actual production rate (equation 8). The desired WIP level is calculated based on the desired production and cycle time (little's law) as in equation (9). The WIP adjustment is controlled by the WIP gap between desired and current WIP level (equation 10).

$$
\begin{gathered}
W I P(t)=P S R(t)-P R(t) \\
D W I P \quad(t)=D P(t) * C T \\
A W I P \quad(t)=\frac{D W I P(t)-W I P(t)}{W A T}
\end{gathered}
$$

The production start rate is set to be equal to the desired production start rate (equation 11) which is the sum of the adjusted WIP and the desired production (equation 12). The desired production is total of the demand forecast (which is 
set to be equal to the average demand) and the adjusted inventory (equations 13 and 14).

$$
\begin{aligned}
& \operatorname{PSR}(t)=\operatorname{DPSR}(t) \\
& \operatorname{DPSR}(t)=\operatorname{DP}(t)+\text { AWIP }(t) \\
& \operatorname{DP}(t)=\text { Max }(0, \text { DemandFore cast }+A I(t) \\
& \text { DemandForecat = MeanDemand } \\
& \quad \text { Customer Orders Fulfillment: }
\end{aligned}
$$

Customer orders are fulfilled by order fulfillment rate, which is controlled by shipment rate (equation 15). The shipment rate is equal to desired shipment rate (equation 16).

$$
\begin{aligned}
& \text { OFR }(t)=\operatorname{ShR}(t) \\
& \operatorname{ShR}(t)=\operatorname{DSR}(t)
\end{aligned}
$$

Desired shipment rate is calculated based on current backlog and shipment time (eq. 17).

$$
D S R \quad(t)=\frac{B(t)}{S T}
$$

The backlog level is calculated as the difference between the order rate (which is exactly equal to the stochastic demand as in equation (18) and order fulfillment rate (equation 19).

$$
\text { OR }(t)=\text { Stochastic Demand }(t)
$$

$$
B(t)=O R(t)-\text { OFR }(t)
$$

Maximum shipment rate is determined by the inventory level and MOPT (equation 20)

$$
\operatorname{MSR} \quad(t)=\frac{I(t)}{M O P T}
$$

\section{IMAPCT OF JIT ON INVENTORY DYNAMICS}

The impact of adopting the JIT lean policy on the developed production system is analyzed in this section. The analysis explores the dynamics of the system inventory since the inventory level is a typical performance metric in traditional production systems. JIT is policy that aims to synchronize the pace of the whole system. This includes the suppliers, manufacturers and customer orders. One approach to do that is through setting production cycle time equals to the shipment time. In some lean literature, this is referred to as producing at takt time. To examine the dynamics associated with such policy in the modeled system, the cycle time (CT) is set to be equal to shipment time (ST) while the inventory adjustment time (IAT) is changed. The chosen parameters' values for the base case are shown in table 1 . The selected values for the different time parameters are based on the experience of the author with traditional assembly systems.

TABLE I. VALUES FOR THE BASE CASE PARAMETERS

\begin{tabular}{|l|l|}
\hline \multicolumn{1}{|c|}{ Demand Parameter: } & \multicolumn{1}{c|}{ Value } \\
\hline Mean demand & 1000 products \\
\hline Standard Deviation & 200 products \\
\hline Time Step (DT) & 0.125 day \\
\hline Correlation Time (CorT) & 4 days \\
\hline Seed & 10 \\
\hline \multicolumn{1}{|c|}{ System Parameters: } & \multicolumn{1}{c|}{ Value } \\
\hline Shipment time (ST) & 3 days \\
\hline Cycle time/1 batch (CT) & 3 days \\
\hline WIP adjust time (WAT) & 1 day \\
\hline
\end{tabular}

\begin{tabular}{|l|l|}
\hline MOPT & 1 day \\
\hline Safety stock cover (SSC) & 1 day \\
\hline
\end{tabular}

Figure 2 ( $a, b$ and c) shows the inventory level in response to the stochastic demand for three inventory control policies. The first scenario is to set the inventory adjustment time (IAT) equal to both the cycle time and the shipment time (figure 2-a). The second scenario is to set the inventory adjustment time (IAT) higher than to both the cycle time and the shipment time (figure 2-b). The third scenario is to set the inventory adjustment time (IAT) less than to both the cycle time and the shipment time (figure 2-c). The IAT is the time required to compensate between the required inventory level (usually dictated by the strategic service level) and the current inventory level. IAT can be altered through different replenishment policies that can make it shorter or longer. However, shorter IAT usually comes with extra costs. Analyzing figure 2, it is clear that when IAT is equal to CT and ST (i.e the system is totally synchronized with demand pace), the inventory level witness a sudden rise to fulfill the demand but eventually settle down to a stable level. This indicates a well controlled inventory pattern and cost.

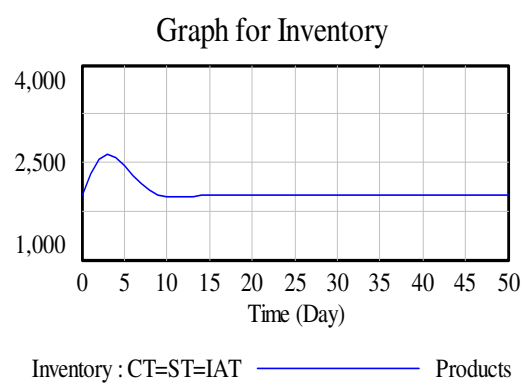

(a)

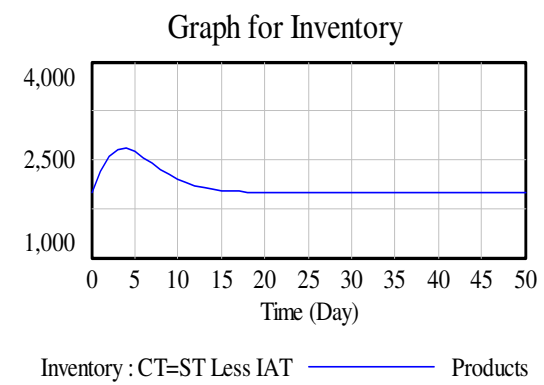

(b)

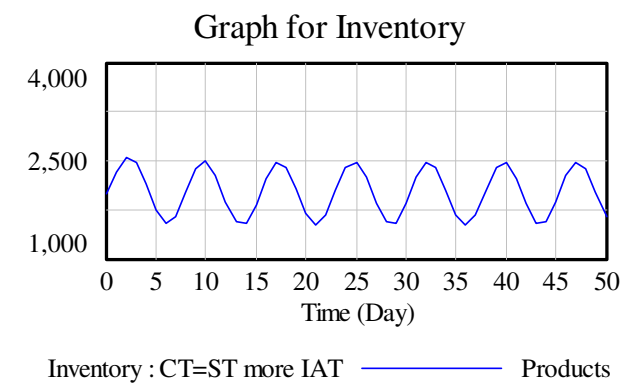

(c)

Figure 2. Effect of IAT on inventory dynamics with JIT policy 
The same can be said when IAT is higher than the other two times. However, a distorting dynamics is generated when IAT is set to be less than the CT and ST. The continuous oscillation in figure 2-c reflects the effort the inventory control system will exert to keep up with the required service level. Such effort affects the system stability as well as comes with high costs.

To demonstrate more the impact of the inventory policies with the adoption of JIT policy on the internal stability of the system, the work in progress (WIP) level is also captured. Figure 3 ( $a, b$ and $c$ ) demonstrates the WIP dynamic under the same three IAT cases. It is clear from the figures that WIP level experience the same dynamics as the inventory level
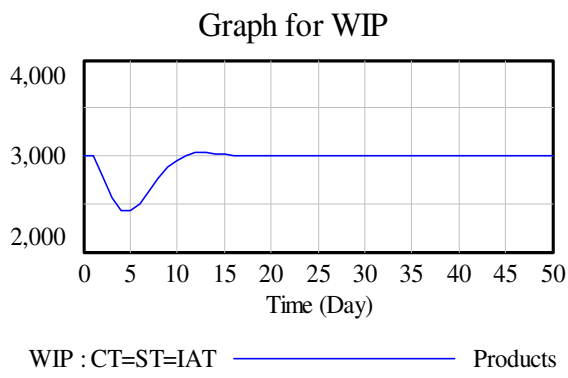

(a)

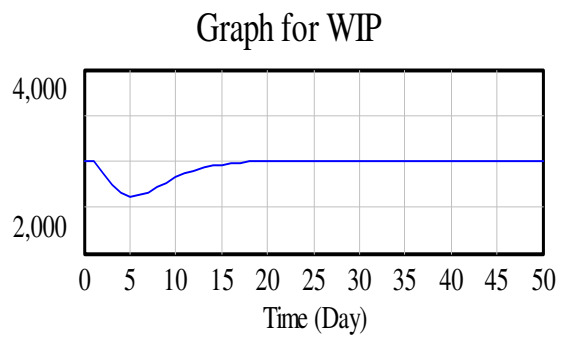

WIP : CT=ST Less IAT — Products

(b)

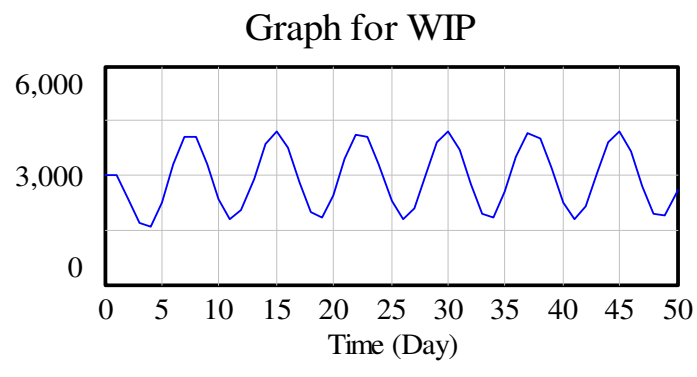

WIP : CT=ST more IAT $\longrightarrow$ Products

(c)

Figure 3. Effect of IAT on inventory dynamics with JIT policy

From figures 2 and 3 the following question can be posted: Being lean and responsive sounds like good advice, but what is the hard-fact inventory management burden of that advice, especially in traditional production systems? The answer would open the door for an important fact that traditional system cannot witness the full benefits of lean manufacturing without going through major changes in their policies and infrastructure.

\section{SUMMARY}

The need for dynamic analysis of lean policies is becoming more evident with the widespread and the continuous calls to implement lean principles and tools among traditional manufacturers. This paper presented a simple system dynamics approach to explore some of the dynamics associated with the lean principle of JIT. The analysis focused on a traditional manufacturing system with typical production and inventory control. The analysis examined the impact JIT on inventory dynamics. Some dynamic issues were demonstrated as well as recommendations and summarized as follows:

- Applying JIT to systems with traditional production and inventory control will not guarantee improvement levels. JIT can bring responsiveness to the manufacturing system, but will also adversely affect the internal system stability.

- To benefit for JIT policies and its responsiveness in traditional systems, the inventory adjustment time (IAT) should always be set to be equal to or greater that the cycle time and shipment time. This means more agile replenishment policies internally and externally (i.e. with the suppliers) are required if IAT as the lead time and shipment time of the manufacturing system gets shorter.

- A trade-off decision is required to balance between the benefit of quick response to market and the costs associated with that to stabilize the production system.

- Traditional systems should start an infrastructure transformation journey to be fully lean. This should happen with gradual implementation of lean tools in parallel.

Future work is still required to explore more dynamic issues in lean manufacturing. For example, the presented dynamic analysis should be extended to multiple stage production. Furthermore, parametric and sensitivity studies for the various parameters involved in the modeling approach would reveal different understandings about the role of these parameters in implementing lean policies to traditional systems..

\section{REFERENCES}

[1] Womack, J., and Jones, D., (2003) Lean Thinking. Free Press, NY

[2] Sanchz, L. and Nagi, R. (2001), A review of agile manufacturing system, International Journal of Production Research, Vol. 39/16, pp. 3561-3600

[3] Shah R., and Ward, P., (2007) Defining and developing of lean production. Journal of Operation Management, Vol. 25, pp. 785-805.

[4] Hogg, D., (2009), "Putting on new glasses for the new world of manufacturing", Manufacturing Engineering, SME, Nov. 2009.

[5] Schonberger, R.J., (1982) Japanese manufacturing techniques: Nine hidden lessons in simplicity, The Free Press: New York. 
[6] Shingo, S., (1989), A Study of the Toyota Production System from an Industrial Engineering Viewpoint, Portland, OR: Productivity Press.

[7] Black, JT., (2007), Design rules for implementing the Toyota production systems, International Journal of Production Research, Vol. 45/16, pp. 3639-3664.

[8] Hu, G., Wng, L., Fetch, S., and Bidanda, B., (2008) A multi-objective model for project portfolio selection to implement lean and Six Sigma concepts. International Journal of Production Research, Vol. 46/23, pp. 6611-6625.

[9] Askin, R.G., and Krishnan, S., (2009) Defining inventory control points in multi-product stochastic pull systems. International Journal of Production Economics, doi:10.1016/j.ijpe.2008.11.020

[10] Detty, R., and Yingling, J., (2000), Quantifying benefits of conversion to lean manufacturing with discrete event simulation: a case study. International Journal of Production Research, Vol. 38/2, pp. 429-445.

[11] Lian, Y., and Van Landeghem, H., (2007). Analysing the effects of Lean manufacturing using a value stream mapping-based simulation generator. International Journal of Production Research, Vol. 45/13, pp. 3037-3058.

[12] Carlson, J. G. and Yao, A. C., (1992), Mixed-model assembly simulation. International Journal of Production Economics, Vol. 26, pp. 161-167.

[13] Welgama, P. S. and Mills,R.G. J., (1995), Use of simulation in the design of a JIT system. International Journal of Operations and Production Management, Vol. 15, pp. 245-260.

[14] Galbraith,L. and Standridge,C.R., (1994), Analysis in manufacturing systems simulation: a case study. Simulation, Vol. 63, pp. 368-375.

[15] Savasar, M. and Al-Jawini, A., (1995), Simulation analysis of just in time production systems. International Journal of Production Economics, Vol. 42, pp. 67-78.

[16] Anderson, E., Morrice, D. and Lundeen, G. (2005), The "physics" of capacity and backlog management in service and custom manufacturing supply chains, System Dynamics Review, 22/3, pp. 217-247

[17] Sterman, J., (2000) Business Dynamics; Modeling Coomplex World. McGraw Hill, NY. 